\title{
SOSIALISASI DAN PELATIHAN SAFETY HOUSE DI KECAMATAN CIBOGO KABUPATEN SUBANG PROVINSI JAWA BARAT
}

\author{
Nunik Ekawandani ${ }^{1}$, Firdhani Faujiah ${ }^{2}$, Avid Inang Rum ${ }^{3}$ \\ 1Teknik Kimia, ${ }^{2}$ Teknik Mesin, ${ }^{3}$ Akuntansi, Politeknik TEDC Bandung \\ ekawandani@poltektedc.ac.id1 ${ }^{1}$,f.firdhani@gmail.com² ${ }^{2}$, avidinang@poltektedc.ac.id ${ }^{3}$
}

\begin{abstract}
ABSTRAK
Kesehatan dan keselamatan adalah aspek penting dalam kehidupan manusia, baik dalam bekerja ataupun dalam kehidupan sehari-hari. Hal tersebut memberikan dampak negatif bila tidak diperhatikan karena kesehatan dan kseselamatan memberikan rasa aman dan nyaman pada kita pada setiap kegiatan. Setiap pekerjaan atau tindakan selalu mempunyai risiko sekecil apapun, apalagi bila pekerjaan yang memang benar-benar mempunyai risiko yang tinggi seperti bekerja di bidang manufaktur atau di bidang migas. Kesehatan dan keselamatan di rumah tinggal pun tak kalah pentingnya, seorang ibu rumah tangga ataupun pembantu rumah tangga mempunyai risiko kegiatan yang tinggi seperti kegiatan di dapur adanya tabung gas, api dari kompor yang menyala, minyak panas, alat rumah tangga bertenaga listrik, bahan kimia yang digunakan saat membersihkan kamar mandi, mencuci, obat anti serangga dan lainnya. Karena prinsipnya dalam K3 yang harus diamankan terlebih dahulu adalah lingkungannya (safe condition) barulah dilakukan pengamanan dalam tindakan (safe act). Kegiatan ini disajikan dalam bentuk workshop, praktik, diskusi, tanya jawab dan tugas mandiri. Hasil evaluasi kegiatan pada awal masih peserta masih sangat awam dengan istilah K3 atau safety house, namun setelah selesai kegiatan ini peserta dapat memahami dan menunjukan sikap safety di rumah dan lingkungan sekitar. Seperti halnya mereka dapat mengidentifikasi berbagai macam bahaya dan mulai menata ulang kembali rumah tinggal mereka.
\end{abstract}

Kata kunci: kesehatan, keselamatan, safety house, risiko, safe condition

\begin{abstract}
Health and safety are important aspects of human life, both at work and in everyday life. This has a negative impact if it is not considered because health and safety provide us with a sense of security and comfort in every activity. Every job or action always has the slightest risk, especially if the work really does have a high risk such as working in manufacturing or in the oil and gas sector. Health and safety at home is equally important, a housewife or housemaid has a high risk of activities such as activities in the kitchen with gas cylinders, fire from burning stoves, hot oil, electric-powered household appliances, chemicals that used when cleaning bathrooms, washing, insect repellent and others. Because the principle in K3 that must be secured first is the environment (safe condition), then safeguards are carried out. This activity is presented in the form of workshops, practices, discussions, question and answer and independent assignments. The results of the activity evaluation at the beginning were that participants were still very unfamiliar with the term K3 or safety house, but after completing this activity the participants could understand and show safety attitudes at home and the surrounding environment. Just as they can identify various kinds of hazards and start rearranging their homes.
\end{abstract}

Keywords: health, safety, safety house, risk, safe condition

\section{A. PENDAHULUAN}

Rumah tempat tinggal merupakan tempat yang sering dianggap sebagai tempat paling aman dan nyaman untuk kita. Namun tanpa kita sadari rumah juga berpotensi sebagai sumber bahaya bagi penghuninya saat melakukan aktivitas didalamnya. Bahaya 
dan resiko didalam rumah yang termasuk didalamnya antara lain adalah kebakaran, keracunan makanan, zat berbahaya, kecelakaan dan lain sebagainya. Ibu Rumah Tangga (IRT) dan juga Pembantu Rumah Tangga (PRT) adalah orang yang aktivitas hariannya banyak dilakukan di dalam rumah, sehingga IRT atau PRT berperan sebagai pengawas sekaligus pelaksana manajemen kesehatan dan keselamatan kerja didalam rumah yang paling rutin, meskipun sikap K3 harus dilakukan oleh semua anggota keluarga yang menghuni rumah tersebut.

Dalam Peraturan (Kementerian Tenaga Kerja, 1996) bahwa terjadinya kecelakaan di tempat kerja sebagian besar disebabkan oleh faktor manusia dan sebagian kecil disebabkan oleh faktor teknis.

Menurut (ILO, 2013), setiap tahun ada lebih dari 250 juta kecelakaan di tempat kerja dan lebih dari 160 juta pekerja menjadi sakit karena bahaya di tempat kerja. Terlebih lagi, 1,2 juta pekerja meninggal akibat kecelakaan dan sakit di tempat kerja.

Program keselamatan kerja di Indonesia dinilai kurang berhasil karena minimnya pembinaan baik formal ataupun non formal, bimbingan, pelayanan informasi, serta monitoring terhadap pelaksanaan setiap kebijakan nasional terkait implementasi teknologi di kalangan masyarakat (Mukhidin, Haritman, \& Kustiawan, 2010).

Kecamatan Cibogo, Kabupaten Subang merupakan salah satu wilayah yang aktif dalam proses pengembangan dan pendidikan masyarakat. Setiap bulannya secara rutin selalu dilakukan kegiatan proses pengembangan dan pendidikan untuk warga masyarakat setempat khususnya bagi para warga dengan keterbatasan pendidikan dan ekonomi. Salah satu program yang rutin dilaksanakan adalah kegiatan PKK untuk seluruh masyarat peremepuan dalam mengembangkan keterampilan dan pengetahuan sebagai pencetak generasi penerus yang lebih baik. Sebagian besar yang mengikuti kegiatan PKK tersebut berprofesi sebagai ibu rumah tangga dengan tinggat pendidikan yang tidak cukup tinggi, meskipun suami mereka memiliki pendidikan yang cukup.

Berdasarkan hasil survey masyarakat di wilayah ini mengeluhkan tentang keamanan dalam rumah, seperti saat menjelang lebaran atau disaat liburan panjang beberapa wilayah rentan sekali untuk terjadi kebakaran dan pencurian. Selain itu dalam kondisi sehari-hari kecelakaan dalam rumah seperti terjatuh, terluka, sakit diare, demam dan penyakit yang berkaitan dengan akibat keracunan atau kecelakaan kerja cukup sering terjadi. Biasanya hal tersebut dianggap lumrah bagi masyarakat setempat, namun seiring dengan kemajuan teknologi dan ilmu pengetahuan melalui media internet, 
televisi dan media lainnya hal tersebut menjadi topik yang perlu diperbaiki. Sehingga perlu dilakukannya proses perbaikan melalui pengetahuan akan keselamatan dan kesehatan kerja, dan praktiknya dalam rumah tangga.

Manajemen Keselamatan dan Kesehatan Kerja (K3) dalam rumah tangga berdasarkan permasalahan yang dialami oleh sebagian besar masyarakat di Kecamatan Cibogo Kabupaten Subang, sangatlah diperlukan. Pengetahuan akan pentingnya menghindari kegitan-kegiatan beresiko, menganalisis adanya resiko dalam kegiatan kecil dan keseharian warga, dan memperbaiki lingkungan mereka, dibutuhkan untuk menciptakan keamanan dan kenyaman kehidupan. Selain itu pemahaman akan keselamatan dan kesehatan kerja merupakan prioritas juga perlu ditanamkan, agar kata lumrah pada kecelakaan seperti jatuh, luka, dan sakit akibat kegiata itu bisa dikurangi sedikit demi sedikit. Sehingga masyarakat memahami dan menerapkan kegiatan yang aman (safe act).

Biasanya sosialisai K3 ini lebih banyak dilakukan di lingkungan kerja seperti industri, instansi ataupun rumah sakit. Sangat sedikit sekali penelitian ataupun sosialisai K3 yang menjadikan rumah tinggal sebagai subjeknya. Padahal pemberitaan mengenai kecelakaan/ bencana dari rumah tinggal sangat banyak sekali. Dengan sosialisasi dan worshop ini diharapkan masyarakat semakin peduli dan dapat menerapkan K3 dalam kegiatan sehari-hari.

\section{B. LANDASAN TEORI}

\section{Sosialisasi}

Menurut kamus besar bahasa Indonesia sosialisasi adalah proses belajar seorang anggota masyarakat untuk mengenal dan menghayati kebudayaan masyarakat dalam lingkungannya, atau upaya memasyarakatkan sesuatu sehingga men-jadi dikenal, dipahami, dihayati oleh masyarakat; pemasyarakatan. Sehingga masyarakat menjadi paham dan dapat menerapkan setiap materi sosialisasi dalam kehidupan sehariharinya.

\section{Safety House}

Kesehatan dan keselamatan kerja (K3) merupakan aspek penting dalam kehidupan masyarakat. Berdasarkan Undang-undang K3 No. 1 Tahun 1970 yang mengatur tentang keselamatan kerja, yaitu mencakup ruang lingkup yang didalamnya terdapat kegiatan/usaha, yang menggunakan bantuan manusia, serta terdapat bahaya dalam 
lingkungan tersebut maka harus dilakukan prosedur Kesehatan dan Keselamatan Kerja. Selain itu Kesehatan dan Keselamatan Kerja juga diatur oleh PERMEN Tenaga Kerja No.Per.05/MEN/1996 yang isinya menjelasakan tentang sistem manajemen K3 yang secara keseluruhan meliputi aspek organisasi, perencanaan, tanggung jawab, pelaksanaan, prosedur, proses dan sumber daya yang dibutuhkan bagi pengembangan, penerapan, pencapaian, pengkajian dan pemeliharaan kebijakan K3 dalam rangka pengendalian resiko pada kegiatan kerja agar terciptanya tempat kerja yang aman, efisien dan produktif.

Factor penyebab kecelakaan seperti dikemukakan oleh H.W Heinrich (1930) dalam (Ramli, 2010) Tindakan tidak aman dari manusia (unsafe act) tindakan ini dapat membahayakan diri sendiri ataupun orang lain . Lingkungan yang tidak aman (unsafe condition) adalah salah satu ketidakamanan dalam lingkungan kerja misalnya penempatan mesin, penyimpanan bahan kimia, sirkulasi udara, pencahayaan ruang yang tidak sesuai dan yang lainnya.

Berikut 9 bahaya umum yang sering terjadi di rumah tangga menurut (Edward , 2019): 1) terjatuh; 2) kebakaran; 3) paparan rendah karbon monoksida; 4) tersedak; 5) terpotong; 6) keracunan; 7) tercekik; 8) tenggelam; 9) luka bakar. Bahaya tersebut umumnya terjadi karena lengah dan kurang kesadaran tentang bahaya. Dalam (Krieger \& Jacobs, 2011) bahwa memahami, mengidentifikasi, dan menghilangkan bahaya yang mungkin ada di rumah Anda, dapat melindungi kesehatan keluarga.

Pelatihan dan sosialisasi tentang manajemen Keselamatan dan Kesehatan Kerja merupakan salah satu solusi untuk meningkatkan pengetahuan para ibu rumah tangga dan warga masyarakat dalam meningkatkan kesehatan dan keselamatan kerja dilingkungan rumah mereka. Pelatiahan tersebut akan bersikan tenang pengetahuan umum tentang Keselamatan dan Kesehatan Kerja, mengenali apa itu safety, hazard dan risk, manajemen resiko, analisis lingkungan kerja, perbaikan dan penanganan keselamatan di lingkungan kerja, dan di ikuti dengan evaluasi berkala akan Keselamatan dan Kesehatan Kerja dirumah tinggal.

Tujuan dari pelatihan tersebut adalah untuk membantu mencipatakan kenyamanan dan ketentraman hidup masyarakat, melalui pengetahuan yang membangun kesadaran akan lingkungan rumah tinggal yang sehat dan aman. Sehingga masyarakat akan terdorong untuk berpikir dan terampil dalam menganalisis kondisi lingkungan rumah 
mereka agar nyaman untuk dihuni serta aman untuk keluarga, khususnya bagi anggota keluarga yang masih kecil dan lanjut usia.

\section{Kecamatan Cibogo}

Cibogo merupakan sebuah kecamatan yang berada di Kabupaten Subang, Provinsi Jawa Barat. Topografi Cibogo adalah dataran rendah dan berbukit dengan ketinggian 140 meter di atas permukaan laut. Mempunyai 9 desa terdiri dari Belendung, Cibalandong Jaya, Cibogo, Cinangsi, Majasari, Padaasih, Sadawarna, Sumurbarang, dengan kepadatan pendudukanya 5.371 jiwa/km2. Batas wilayah kecamatan Cibogo sebelah utara dengan kecamatan Cipunagara, sebelah selatan dengan kecamatan Cijambe, sebelah barat dengan kecamatan Sumedang, dan sebelah timur dengan kecamatan Subang.

\section{METODE PELAKSANAAN}

\section{Kerangka Kegiatan}

Untuk mencapai tujuan dan target dari pelatihan yang dilakukan makan perlu dilakukan beberapa tahap, seperti proses pengecekan awal untuk melihat sejauh mana kemampuan dan pengetahuan dari masyarat, proses pelaksanaan pelatihan, praktik lapangan, dan evaluasi. Gambar 1. Merupakan alur dari pelaksanaan pelatihan.

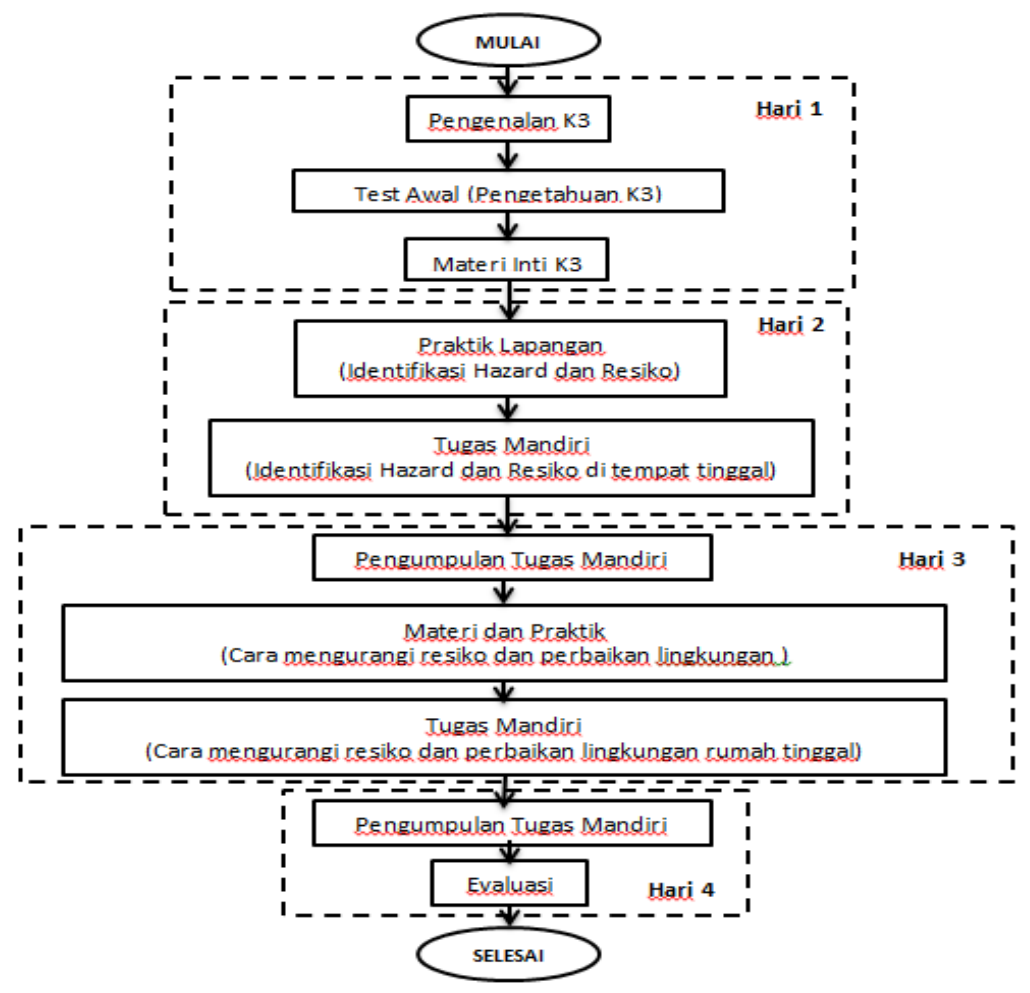

Gambar 1. Alur Program Pelatihan 
Berdasarkan alur proses pendekatan pemecahan masalah tersebut disusunlah rencana dan penjawalan kegiatan dari pelatihan yang akan dilaksanakan. Kegiatan di ikut oleh anggota PKK dari beberapa kelurahan di Kecamatan Cibogo, Kabupaten Subang Jawa Barat. Pelaksanaan kegiatan pelatihan dilakukan selama 4 hari dari mulai tanggal 26 hingga 29 April 2017.

\section{Metode Pelaksanaan}

Proses pelatihan dilakukan selama 4 hari berturut-turut. Pelatihan diberikan dalam bentuk workshop dilengkapi dengan pemberian materi ajar (modul), Praktik lapangan dengan memberikan contoh secara langsung diruangan praktik, dan juga praktik mandiri. Pada praktik mandiri peserta diminta untuk melakukan idenfitikasi dan juga pengaplikasian dari materi dan praktik yang telah diajar pada lingkungan di sekitar tempat praktik. Kemudian peserta juga diberikan tugas mandiri dimana peserta ditugaskan untuk mepraktikan hasil pelatihannya ke lingkungan rumahnya secara langsung. Setelah proses pelatihan selama 4 hari selesai, maka akan dilakukan proses evaluasi di bulan berikutnya selama 2 bulan berturut-turut untuk melihat apakah penerapan dari hasil pelatihan berjalan dengan baik. Proses evaluasi dibantu oleh pihak PKK yang bekerjasama dengan pihak Politeknik TEDC Bandung.

\section{HASIL DAN PEMBAHASAN}

\section{Realisasi Pelaksanaan Kegiatan}

Kegiatan dilaksanakan sesuai dengan jadwal selama 4 Hari berturut-turut. Tempat pelaksanaan kegiatan Sosialisasi dan Pelatihan Keselamatan dan Kesehatan Kerja (K3) Rumah Tinggal (Safety House) ini bertempat di Aula Desa Sadawarna, Kecamatan Cibogo, Subang.

\section{Sasaran Kegiatan}

Sasaran kegiatan Pengabdian kepada masyarakat ini adalah ibu-ibu PKK Kecamatan Cibogo. Ibu-ibu PKK tersebut merupakan gabungan dari 9 Desa atau Keluarahan yang berada dibawah Kecamatan Cibogo, Subang. Peserta yang mengikuti kegiatan tersebut berjumlah 40 orang. Peserta yang hadir dibatasi, untuk setiap Desa mewakilkan tidak lebih dari 4 angota PKK yaitu Ketua, Wakil Ketua, Sekretaris, dan Bendahara PKK Desa. Pembatasan tersebut dikarenakan kapasitas ruangan yang akan digunakan terbatas. 
Peserta yang mengikuti pelatihan berjumlah 40 orang ibu-ibu PKK dari 9 Desa. Mayoritas dari peserta sekitar 70\% merupakan ibu rumah tangga dengan latar belakang pendidikan tertinggi SMA dan merupakan penduduk asli Subang secara turun temurun. Sekitar 30\% peserta merupakan wanita karir, meskipun pekerjaan yang dilakukan beragam dan sebagain besar adalah pedagang kecil, guru TK, dll, dengan pendidikan tertinggi S1. Selain itu juga, para ibu-ibu wanita karir tersebut sebagain besar merupakan pendatang dari luar Subang yang menikah dengan warga Subang atau ditugaskan di Subang.

\section{Pembahasan}

\section{Temuan Hasil Evaluasi}

Serangkaian kegiatan sosialisasi ini memberikan temuan-temuan bagi pelaksana kegiatan. Temuan tersebut diantaranya:

1. Pada hari pertama, merupakan sosialisasi dan pengenalan awal dari materi. Sebagian besar peserta belum mengetahui apa itu Keselamatan dan Kesehatan Kerja (safety), bagaimana pentingnya safety dan apa itu sikap safety.

2. Hari Kedua, dilakukan tindakan praktik pada lingkungan sekitar atau kantor Desa. Kegiatan interaksi yang terjadi sangatlah aktif, para peserta mulai memahami secara langsung bagaimana safety itu dan praktinya dilapangan.

3. Hari Ketiga, dilakukan tindakan praktik pada lingkungan rumah tinggal disekitar Desa. Kegiatan interaksi antara warga dan peserta berlangsung aktif, para peserta mulai mampu untuk mengindentifikasi bahaya yang ada disekitar rumah tinggal warga. Kemudian diberikan tugas mandiri untuk melakukan identifikasi beserta solusinya dirumah.

4. Hari Terakhir, dilakukan sesi pembahasan dari tugas mandiri pada hari sebelumnya. Peserta sebagian besar sudah mampu melakukan identifikasi bahaya dan mengaplikasikan sikap safety melalui beberapa cara, seperti perbaikan tatanan dapur secara visual control, memasang alat bantu warna pada sisi-sisi rumah yang cukup berbahaya untuk menjadi perhatian keluarga dan lain sebagainya.

Berdasarkan temuan yang telah dipaparkan diatas, dapat dilihat bahwa peserta mengikuti kegiatan dengan antusias. Selama 4 hari tersebut peserta telah mampu menunjukan beberapa sikap safety, meskipun pada awalnya mereka tidak tahu sama 
sekali. Selain itu anggapan bahwa bahaya seperti jatuh, terpercik minyak saat menggoreng, luka, dan lain sebagainya adalah hal yang biasa, sudah mulai bergeser dan disadari bahwa hal tersebut berdapak merugikan apalagi dalam jangka waktu yang panjang.

\section{E. KESIMPULAN}

Berdasarkan hasil pelaksanaan kegiatan yang telah dilakukan, dapat ditarik beberapa kesimpulan, sebagai berikut:

1. Pengetahuan dan kesadaran akan pentingnya Keselamatan dan Kesehatan Kerja (K3) perlu ditanamkan mulai saat ini pada warga masyarakat umum. Hal ini ditunjukan melalui temuan awal para warga yang masih menganggap suatu bahaya itu lumrah padahal menyebabkan resiko yang cukup.

2. Pelatihan dan Sosialisasi K3 ini memberikan hasil yang memuaskan, karena sebagian besar peserta sudah mulai menunjukan sikap sigap dan safety dalam praktik dirumah tinggal masing-masing.

3. Pelatihan ini dalam jangka panjang dapat mengurangi kasus kasus cidera dan celaka yang terjadi di rumah tinggal. Hal tersebut berujung pada kenyamanan, keamanan dan kesejahteraan dari masyarakat.

Keselamatan dan Kesehatan Kerja (K3) sudah merupakan hal yang sangat umum bagi dunia Industri dan juga instansi formal atau non formal. Namun kesadaran akan pentingnya K3 di rumah tinggal masih sangatlah minim. Sehingga perlu dilakukan sosialisasi-sosialiasi seperti ini dibeberapa daerah lain terutama di lingkungan padat penduduk.

\section{F. DAFTAR PUSTAKA}

Edward, Rebecca. (2019). Safety Hazards to Watch Out for Around the House. https://www.safewise.com/blog/safety-hazards-to-watch-out-for-around-the-house/ (diakses 25 Maret 2019).

International Labour Organization (ILO)., 2013, Keselamatan dan Kesehatan Kerja: Sarana untuk Produktivitas. Modul 5, SCORE: Jakarta.

Meredith Corp (2016). 10 Surprising Safety Hazard. Artikel di www.parents.com.

PERMEN Tenaga Kerja No.Per.05/MEN/1996. https://toolsfortransformation.net/wpcontent/uploads/2017/05/Per-Men-Naker-No.5-thn-1996-ttg-SMK3 E.pdf

Illinois Department of Public Health. HEALTHYHOMESKeeping Your HomeHealthy and Safe. http://www.idph.state.il.us/HealthWellness/HealthyHomes.pdf 
Ramli, Soehatman.(2010). Sistem Manajemen keselamatan \& kesehatan Kerja OHSAS 18001.Jakarta: Dian Rakyat.

ILO. (2013). Keselamatan dan Kesehatan Kerja Keselamatan dan Kesehatan Sarana untuk Produktivitas.

Kementerian Tenaga Kerja. (1996). Sistem Manajemen Keselamatan dan Kesehatan Kerja. Permenaker Nomor 5, 3.

Krieger, J., \& Jacobs, D. E. (2011). Healthy Homes. Making Healthy Places, 170-187. https://doi.org/10.5822/978-1-61091-036-1_11.

Mukhidin, Haritman, E., \& Kustiawan, I. (2010). Sosialisasi Keselamatan Kerja Elektronika Rumah Tangga di Desa Cisaat Kecamatan Ciateur Kabupaten Subang. Bandung. 